\title{
Research on the New Education Mode towards Clothing Education in Colleges and Universities under the Background of Ability Guided Value
}

\author{
Jiarong $\operatorname{Han}^{1}$ \\ ${ }^{1}$ Northeast Dianli University ,Jilin , Jilin 132012 China
}

\begin{abstract}
In this paper, we conduct research on the new education mode towards clothing education in colleges and universities under the background of ability guided value. Applied talent is to apply professional knowledge and professional skills in social practice of specialized personnel a line is fluent in social production and social activities of basic knowledge and basic skills. Ability evaluation index is not fixed, combining with the change of market demand for talents and the improvement of unit of choose and employ persons of evaluation standard. Our reform combines the needs of the society and the class education which will enhance the students' ability. In the near future, we plan to conduct more corresponding research to polish the current methodology.
\end{abstract}

Keywords: Education Mode; Clothing Education; Ability Guided; Colleges and Universities.

\section{Introduction}

Dress and clothing design major, after years of development and research of vocational and technical school dress design major and curriculum teaching methods have a certain scale and formed a certain teaching mode, has a set of relatively complete costume design professional teaching system, training a batch of talents of the clothing industry [1]. But with the deepening of the economic development, consumer appreciation level continuously improve, mainstream culture cycle is shorten, refine demand and the market demand oriented goal of fostering applied and innovative fashion design professionals gradually become one of the teaching goals of vocational school. With the globalization of economy and society and the popularization of higher education, college students increasingly serious employment situation, the attention based on ability, strengthen the cultivation of professional talents in colleges and universities has become the urgent needs of the social development and the development of higher education. Applied talents is to apply professional knowledge and professional skills in social practice of specialized personnel, a line is fluent in social production and social activities of basic knowledge and basic skills, mainly engaged in the production line of technical or professional. Development of applied talents education is industry developed countries and regions to society demand and the rapid development of mass education background of common [2].

Applied talents training mode based on ability training center of gravity of talent cultivation system, multi-level, personalized training characteristics, requirements to build and perfect aimed to improve the basic theory and basic knowledge theory curriculum system, in order to improve the basic skills and professional skills as the goal of practical curriculum system, in order to improve the comprehensive ability and extend the professional diathesis developing system as the goal. Combined with higher vocational talents training standards and industry position requirements for dress design talents, costume design course is in the process of design to break 
the costume design course of the original subject system, to reconstruct the knowledge and skills system. Adopts the design project and task driven teaching mode, using the integration of teaching practice of "cluster design project studio" teaching platform, using the grouping project oriented teaching method and project teaching method, through the team cooperation, to cultivate students engaged in garment design necessary to found the problem ability, judgment ability, public communication, management ability and the professional quality. In general, the education pattern could be divided into the following parts. (1) Typical case teaching method. Through the analysis of real cases, the student can to enterprise's actual operation situation has a deep understanding of by making a virtual case can cultivate students found the problem, thinking and problem solving skills. (2) The task driven teaching method. This theory can be incorporated into action in the process of teaching method is different from the traditional theory after the practice of teaching ideas first, can greatly improve students' level of theory. At the same time, this kind of take the student as the main body in the action of the teaching method is a good way to stimulate students' interest in learning, help students master the methods of work, and cultivate the habit of active learning. (3) Ability to improve teaching methods. Through the typical professional task, can be a general understanding of the students, he learned what is the main work content. At the same time, students can also learn his job in the role of the whole work process, and able to work in a whole scene to recognize that their own can do valuable work [3-4].

In this paper, we conduct research on the new education mode towards clothing education in colleges and universities under the background of ability guided value. Project oriented type teaching is based on the integrity of the teaching idea, through a complete finishing a project, from the information collection, planning, scheme selection, the implementation of the target, information feedback to the results of evaluation, students participate in the whole process each link and become the master in their activities. In the following sections, we will discuss the method in detail.

\section{Our Proposed Method and Model}

The Principles of Ability Guided Value. Applied talents should have the ability to participate in the basic line, at the same time would like to start from the basic work to improve their work solidly. But applied undergraduate talents is not equal to low level talents, should be reasonable to distinguish in the training objectives, by "the knowledge standard" to "quality standard" and the cultivation of outstanding professional and technical application ability. By inheriting type talent cultivation to the transition of the innovative talents cultivation, highlight the personality development and innovation ability, thus truly highlight the practical applicability of this professional characteristics. Ability evaluation index is not fixed, combining with the change of market demand for talents and the improvement of unit of choose and employ persons of evaluation standard, timely adjust the center of gravity of talent cultivation, to optimize the modular curriculum design, reflect social evaluation of professional talents in the new period. Ability evaluation indexes must be continuously detailed at the same time, according to each course module, design specific, measurable, related evaluation project. Multi-dimensional comprehensive index evaluation system, through the evaluation model of enterprise talent demand which will refining capacity index, contrast to develop discipline education ability development indicators, the combination of optimization of each index, corresponding to develop relevant knowledge module design and teaching methods. At the same time, according to the market demand for talents, and constantly adjust the index weight, restructuring curriculum knowledge module, 
strengthening the connotation of technology applied knowledge system, realize the talents training and enterprise needs matching ability development model [5].

Training applied talents can't weaken the theory study, because practice only under the guidance of the correct theory can achieve maximum utility. Ignore learning theory can bring hidden trouble to the practice, but also bad for their career development. In the teaching theory of learning should avoid long from actually and according to ability evaluation index, effective extraction theory learning knowledge, modular curriculum structure, to theoretical study in practice and enhance the students' understanding of the knowledge system.

The Clothing Education Reform. Clothing is a practical strong professional, effect picture better, theory more proficient and finally could not form apparel products, such as would be an armchair strategist. So on the clothing in the curriculum and should pay attention to the proportion of theory course and practice course distribution and integration. Project teaching take the student as the main body, with teachers as the leading, with practice as the goal of open teaching, make students actively participate in the curriculum innovation in the process of learning and practice, using the new study the knowledge, through the actual project inspection, to solve the problems in the practice process. Project teaching is the major changes to the traditional classroom teaching mode, it not only makes the classroom teaching atmosphere become more active, also can make students get professional training, to cultivate the students' vocational skills and professional awareness of comprehensive found a feasible way. Clothing should be a combination of art and technology of inter-discipline, the only skill workers blend to achieve good product. So curriculum ideas of garment specialty in colleges and universities should be artistic accomplishment, design thought and the combination of engineering course, achieve mastery through a comprehensive study mutually, too much emphasis on which part is not appropriate. Different professional clothing in the directory, both engineering and arts, although the emphasis on the research direction, but two categories on the curriculum courses should take into account, can be focused on the scale.

The principles of the education reform and modification could be summarized into the following parts. (1) Determine the project teaching. Mainly are the real demand of clothing enterprise project for the standard, through teaching combined with clothing enterprise product of project, make the students understand the clothing product development or manufacturing process, familiar with the garment enterprises of different job requirements and should have professional knowledge and ability to work. Master the apparel product design and development requirements and technical standards and requirements of each section of production, to improve students' practice ability. (2) Project teaching plan. General project director discussed by teachers and clothing enterprise, according to the structure and technology design of course and course of different classes and the specific requirements of the project development, determine the project teaching process and implementation. Depending on the design direction, design course can be divided into several modules design. Requires teachers to each group of students to complete the project, want to have an overall understanding of master students in each group to complete the project in the common problems and personality to smell problem, which pointed out the advantages and the deficiencies of each group of students, in the learning process should pay attention to strengthening the study of what knowledge, cultivating students' practice ability and innovation ability.

The New Education Mode towards Clothing Education. Project-oriented teaching practice, determines the enterprise inevitably is the indispensable place to school practice 
teaching. Therefore, to establish the good "win-win" cooperation mechanism between colleges which is the fundamental guarantee implementation of project oriented teaching. Costume design project oriented type teaching mode requires close to the first production line, and enterprise cooperation and development, project implementation. In the process of teaching, give full play to the students as the main body of learning initiative and active role, working process oriented design. Teaching situation, design the teaching contents in real work tasks as the carrier, to the action of the cooperation between teachers and students and students, the action-oriented teaching method through each teaching situation, change the traditional education evaluation method, with professional ability, method ability, social ability formation after integration practice ability as the evaluation standard. In the figure one, we illustrate the new education mode under the guidance of information sharing and ability enhancement.

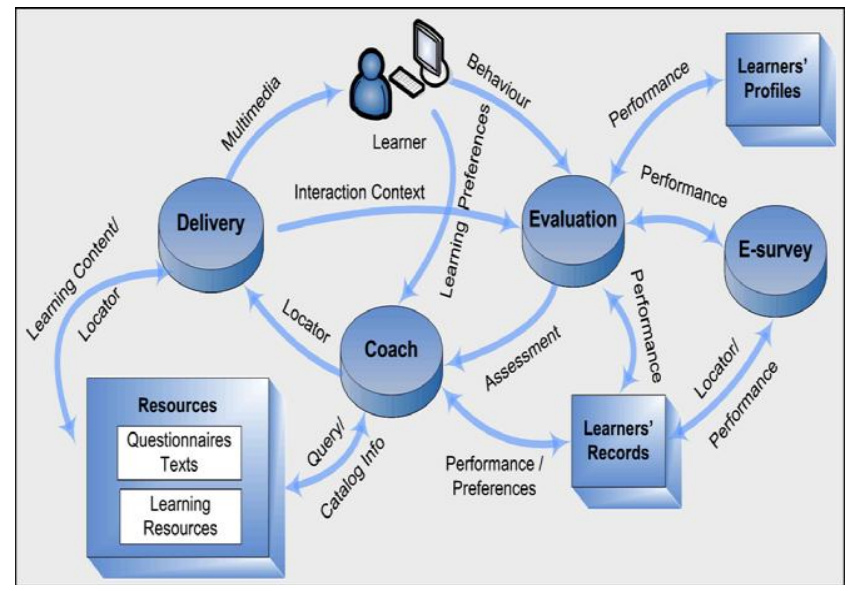

Figure 1.The New Education Mode

Professional classroom with clothing consumption of terminal market, on the basis of the organic combination of building real work scenarios of clothing product development, thus forming the integration of teaching process and the working process of the integration of classroom, teaching environment and work environment and practice place unity of work-integrated learning, action-oriented teaching mode of teaching to do integration.
Integrated use of the typical case analysis in the process of teaching, task driven, project orientation which is based on the working process of the teaching methods to arouse students' learning enthusiasm, cultivate the students' innovation spirit and practice ability. Complete the working process of the project of teaching put forward higher requirements for teachers, it requires that the teachers at the same time of good professional knowledge attainment, with high level of practical operation ability, strong ability of project design and project guidance and good ability of organization of teaching. Create a fusion of theory teaching and practice teaching, curriculum system, leather with subject system design course, the most institutes according to the curriculum teaching practice, separately from the theory and practice teaching system. Emphasis on vocational skills training, highlight the status of the practice teaching, to practical skills as the main body, integration of theoretical knowledge and combining students' vocational skills training and classroom teaching, integrated teaching. Create a fusion of theory teaching and practice teaching, curriculum system, leather with subject system design course, the most institutes according to the curriculum teaching practice, separately from the theory and practice teaching system. Emphasis on vocational skills training, highlight the status of the practice teaching, to practical skills as the main body, integration of theoretical knowledge, combining students' vocational skills training and classroom teaching based integrated teaching methodology. We firmly believe that through the reform, the performance of the education will be enhanced.

\section{Conclusion}

In this paper, we conduct research on the new education mode towards clothing education in colleges and universities under the background of ability guided value. With the globalization of economy and society and the popularization of higher education, college students increasingly 
serious employment situation, the attention based on ability, strengthen the cultivation of professional talents in colleges and universities has become the urgent needs of the social development. Garment industry, business practice and the research conclusion of the expert interview, according to the clothing enterprises in different stages of the product development process and task of the job requirements, to determine the learning areas, forming work tasks by numerous, capacity requirements from low to high incremental learning situation, the professional knowledge and vocational skills gradually into every learning situations. Our reform will not only enhance the ability of the students, but also level-up the teaching ability of the teachers which has significant meaning.

\section{References}

[1] Li-Yan S I, Zhang S W. On cheerleading's aesthetic features and aesthetic education research in colleges and universities of Anhui[J]. Journal of Shaoguan University, 2014.

[2] Huang C, Department S. Characteristics and Cultivation Strategy of Innovative Physical Education Teacher in Colleges and Universities[J]. Hubei Sports Science, 2014.

[3] Zhu X, Wang F. The Reform of Education in Colleges and Universities and Innovative Sports Talents Cultivation[J]. Sports Forum, 2014.

[4] Yang G, Zheng S, Shi S, et al. Moral Education of Post-90s Students in Normal Colleges and Universities under the New Media Environment[J]. Journal of Dali University, 2014.

[5] Zhang X L, Song B N. The Exploration of the Teaching of "Practical" Moot Court in the Law Education at Colleges and Universities[J]. Journal of Jining Normal University,

2014 